\title{
Seasonal changes in gravity wave activity measured by lidars at mid-latitudes
}

\author{
M. Rauthe ${ }^{1, *}$, M. Gerding ${ }^{1}$, and F.-J. Lübken ${ }^{1}$ \\ ${ }^{1}$ Leibniz-Institut für Atmosphärenphysik an der Universität Rostock, Kühlungsborn, Germany \\ * now at: Institut für Meteorologie und Klimaforschung, Universität Karlsruhe, Karlsruhe, Germany \\ Received: 18 June 2008 - Published in Atmos. Chem. Phys. Discuss.: 17 July 2008 \\ Revised: 16 September 2008 - Accepted: 7 October 2008 - Published: 25 November 2008
}

\begin{abstract}
More than 230 nights of temperature measurements between 1 and $105 \mathrm{~km}$ have been performed at the Leibniz-Institute of Atmospheric Physics in Kühlungsborn with a combination of two different lidars, i.e. a RayleighMie-Raman lidar and a potassium lidar. About $1700 \mathrm{~h}$ of measurements have been collected between 2002 and 2006 . Apart from some gaps due to the adverse weather conditions the measurements are well distributed throughout the year. Comprehensive information about the activity of mediumand low-frequency gravity waves was extracted from this data set. The dominating vertical wavelengths found are between 10 and $20 \mathrm{~km}$ and do not show any seasonal variation. In contrast the temperature fluctuations due to gravity waves experience a clear annual cycle with a maximum in winter. The most significant differences exist around $60 \mathrm{~km}$ where the fluctuations in winter are more than two times larger than they are in summer. Only small seasonal differences are observed above $90 \mathrm{~km}$ and below $35 \mathrm{~km}$. Generally, the fluctuations grow from about $0.5 \mathrm{~K}$ up to $8 \mathrm{~K}$ between 20 and $100 \mathrm{~km}$. Damping of waves is observed at nearly all altitudes and in all seasons. The planetary wave activity shows a similar structure in altitude and season as the gravity wave activity which indicates that similar mechanisms influencing different scales. Combining the monthly mean temperatures and the fluctuations we show that the transition between winter and summer season and vice versa seems to start in the mesopause region and to penetrate downward.
\end{abstract}

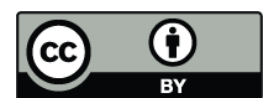

Correspondence to: $\mathrm{M}$. Rauthe (monika.rauthe@imk.uka.de)

\section{Introduction}

In recent years gravity waves in the atmosphere have been the subject of intense research because they play a decisive role for atmospheric circulation, structure, variability and composition (see review by Fritts and Alexander, 2003, and references therein). Generated in the troposphere/lower stratosphere gravity waves propagate upward and deposit their energy and momentum when breaking or being filtered. They greatly influence the winds and thermal structure of the middle and upper atmosphere (e.g. Lindzen, 1981; Holton, 1982; McLandress, 1998; Holton and Alexander, 2000).

A number of different techniques have been used to observe and analyse gravity waves in the lower, middle and upper atmosphere (e.g. Wilson et al., 1991b; Eckermann et al., 1995; Fritts and Hoppe, 1995; Hertzog et al., 2002). However, there have been only few measurements which resolve gravity waves with small vertical and horizontal scales and short periods. These include measurements by satellites (e.g. Wu and Waters, 1996a; Krebsbach and Preusse, 2007; Sofieva et al., 2007; Alexander et al., 2008), radars (e.g. Nakamura et al., 1996; Serafimovich et al., 2005), OH-Imagers (e.g. Stockwell and Lowe, 2001; Suzuki et al., 2004), radiosonde soundings (e.g. Allen and Vincent, 1995; Vincent and Alexander, 2000) and rocket soundings (e.g. Eckermann et al., 1995; Rapp et al., 2004). The lidar is the only technique which has an appropriate time and height resolution over the entire altitude range from the troposphere up to the lower thermosphere for resolving low- and mediumfrequency gravity waves, which are an important part of the wave spectrum (see review by Fritts and Alexander, 2003). But most gravity wave analyses of lidar measurements cover only a small altitude range because only one single lidar

Published by Copernicus Publications on behalf of the European Geosciences Union. 


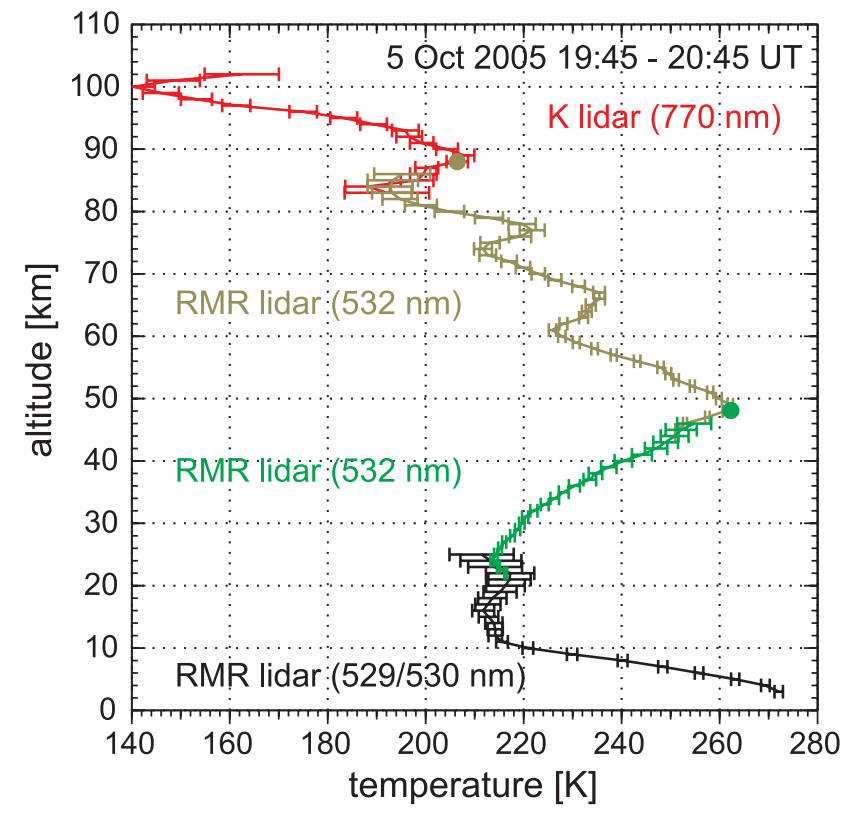

Fig. 1. Temperature profile obtained from a combination of different lidar techniques measured on 5 October 2005, 19:45-20:45 UT, above Kühlungsborn. The coloured dots at $88 \mathrm{~km}$ and $48 \mathrm{~km}$ indicate the start value for the Rayleigh temperature retrieval.

technique is used (e.g. Gardner and Voelz, 1987; Wilson et al., 1991a,b; Schöch et al., 2004). Just a few case studies include the whole altitude range relevant for gravity waves from their source (troposphere/lower stratosphere) to their main dissipation region (mesosphere) (e.g. Dao et al., 1995; Sica et al., 1995; Williams et al., 2004). These case studies do not allow to analyse the seasonal variation of gravity wave activity.

The purpose of this paper is to present mean features of gravity wave activity at mid-latitudes as function of season and altitude using the combined data set of two lidars. The main focus is the analysis of vertical wavelengths, amplitudes and potential energies in the stratosphere and the mesosphere. This kind of ground-based observation is needed to understand the spectrum of gravity waves present in the atmosphere. Here, temperatures between 1 and $105 \mathrm{~km}$ are measured. They are calculated from data of two different lidars, namely a Rayleigh-Mie-Raman lidar (RMR lidar) and a potassium lidar. Both are operated at the Leibniz-Institute of Atmospheric Physics (IAP) in Kühlungsborn, Germany $\left(54^{\circ} \mathrm{N}, 12^{\circ} \mathrm{E}\right)$. For the calculation of temperatures temporal and vertical samplings of $15 \mathrm{~min}$ and $1 \mathrm{~km}$ are used, respectively. This range of scales is unique and can only be covered by the combination of different lidar techniques (Alpers et al., 2004). Altogether, more than 230 nights with more than $3 \mathrm{~h}$ measurement duration are examined and the presented results extend the winter-summer study of Rauthe et al. (2006).
The paper is organised as follows. In Sect. 2 short descriptions of the observational methods and the calculation of relevant gravity wave parameters are presented. An example including three consecutive nights of measurements finishes this section. The seasonal variability of vertical wavelengths, amplitudes and potential energies are shown in Sect. 3. Section 4 includes a comparison between the monthly mean temperature fluctuations and temperatures to study the transition between the seasons and the different scales of variability. In Sect. 5 the discussion of the results is presented. The conclusions are summarised in Sect. 6.

\section{Lidar systems and data analysis}

This section is divided in three parts which contain the technical base of the paper and one example from the measurements. First a brief description of our lidar systems is given. More details can be found in Alpers et al. (2004). Afterwards the analyses of gravity wave parameters and three consecutive nights of measurements are presented.

\subsection{Measurement techniques}

Temperature soundings from 1 to $105 \mathrm{~km}$ are preformed at IAP by the combination of two different lidar systems. As shown in Fig. 1 three different methods are applied in four altitude regions from the troposphere up to the lower thermosphere. A potassium resonance lidar examines the Doppler broadening of the potassium D1 resonance line by tunable narrow band laser. This technique provides absolute temperatures between $\sim 85-105 \mathrm{~km}$. The altiudinal coverage depends on the width of the potassium layer. With the RMR lidar the Rayleigh backscatter at $532 \mathrm{~nm}$ wavelength is detected which yields atmospheric density profiles (20-90 km). These density profiles can be converted to temperature profiles through integration assuming hydrostatic equilibrium and using an initial temperature value from the potassium lidar. The altitude range is divided in two parts to manage the wide range of signal dynamics. Since February 2004 the effect of stratospheric aerosols are corrected via vibrational $\mathrm{N}_{2}$ Raman signal $(608 \mathrm{~nm})$, before the correction was empirical (for details see Alpers et al., 2004; Gerding et al., 2004). Below $20 \mathrm{~km}$ the rotational Raman backscatter in two narrow wavelength ranges are used to measure the temperature.

One example of a temperature profile integrated over $1 \mathrm{~h}$ is shown in Fig. 1. The statistical uncertainty, which is mainly caused by the photon counting uncertainty is typically 1.5$2.5 \mathrm{~K}$ and does not exceed $10 \mathrm{~K}$. Only in the troposphere the typical observed temperature fluctuations are smaller than the uncertainties of the measurement. Using the start values for Rayleigh temperature retrieval from potassium lidar avoid errors in the upper part of the Rayleigh temperature profile. Comparisons between climatological mean and observed temperature show even differences up to $20 \mathrm{~K}$. Case 
studies demonstrated that taking the start temperature from a climatology mean instead of the potassium lidar would give errors of up to $8 \mathrm{~K}$ in the temperature fluctuations.

To ensure continuous temperature profiles with a good trade-off between statistical uncertainties and temperature fluctuations the following procedure is necessary. The raw data profiles are smoothed applying an altitude-dependent filter ( 0.6 and $3 \mathrm{~km}$ at 40 and $80 \mathrm{~km}$, respectively) and a running mean over $1 \mathrm{~h}$ with $15 \mathrm{~min}$ shift in time. At the end, the temperature data are binned into $1 \mathrm{~km}$ altitude ranges.

\subsection{Gravity wave analysis}

The calculation of parameters which characterise the gravity wave activity is based on the temperature deviations from the nightly mean $(\Delta T)$. These values are used to calculate the mean temperature fluctuations $(|\overline{\Delta T}|)$ as an altitudedependent parameter, which are called temperature fluctuations in the following. With the temperature deviations the gravity wave potential energy density (GWPED) is derived. Two different values are distinguished: the potential energy per mass $E_{\text {pot,M }}$ and the potential energy per volume $E_{\mathrm{pot}, \mathrm{V}}$. The potential energy per mass can be calculated directly from our measurements

$E_{\mathrm{pot}, \mathrm{M}}=\frac{1}{2} \frac{g^{2}}{N^{2}}\left(\frac{\tilde{\rho}}{\bar{\rho}}\right)^{2} \approx \frac{1}{2} \frac{g^{2}}{N^{2}}\left(\frac{\tilde{T}}{\bar{T}}\right)^{2}$.

This value depends on gravitational acceleration $(g)$, Brunt-Väisälä frequency $(N)$ and density $(\rho)$ or temperature $(T)$. Since the amplitudes $(\tilde{T})$ of the single waves are usually not known in observational studies which measure the net amplitude of many superimposed waves, means of amplitudes are used $(\tilde{T}=\Delta T)$. Note that this substitution results in slightly lower values. In addition, we would like to point out that only single profiles are measured by the lidar, i.e. since the waves propagate also horizontally, they propagate in and out of the measurement volume. Therefore, the waves are regarded as statistical ensemble. Multiplying $E_{\mathrm{pot}, \mathrm{M}}$ with density gives $E_{\mathrm{pot}, \mathrm{V}}$. The density is taken from a reference atmosphere like CIRA-86 (Fleming et al., 1990), because the results are not significantly changed if we use densities derived from the measurements itself. Therefore, we abstain from this procedure and use climatological values. As is well known the conserved quantity is the wave action, which is defined as potential energy divides by the intrinsic wave frequency. However, if the $E_{\mathrm{pot}, \mathrm{M}}$ does not increase exponentially or rather $E_{\mathrm{pot}, \mathrm{V}}$ is not approximately constant with altitude this can indicate wave dissipation.

Apart from amplitudes the vertical wavelength $\left(\lambda_{z}\right)$ is also an important but not well-known property of gravity waves. Vertical wavelengths are calculated by wavelet analyses of single altitude profiles. A Morlet wavelet of fifth order, which is a good approach for many geophysical applications, is used (Torrence and Compo, 1998). The minimum and maximum wavelength is $4 \mathrm{~km}$ and $60 \mathrm{~km}$, respectively. Using 100 wavelengths (uniformly distributed in the frequency) an adequate resolution is ensured. Note the maximum distance between the resolved wavelengths amounts only $1.5 \mathrm{~km}$. Because of our very large altitude range it is possible to derive vertical wavelengths from 5 up to $50 \mathrm{~km}$. The nightly mean spectrum provides the mean characteristics of the single night. To determine the dominating wavelength at each altitude up to three maxima are calculated from this nightly mean spectrum. The periods are also determined by the wavelet analyses in a similar way as for $\lambda_{z}$ with appropriate parameters. Periods are calculated from the time series at every altitude. Note that the periods $(P)$ are obtained relative to the ground-based station (intrinsic values may be different because of Doppler shift).

\subsection{Example of three consecutive nights}

To demonstrate the night-to-night variability of our observations, three consecutive nights in October 2005 are presented in this section. Besides measurements at night from both lidars between 1 and $105 \mathrm{~km}$ there are measurements between 85 and $95 \mathrm{~km}$ during daylight conditions from the potassium lidar. Due to the weak signal the time resolution has to be reduced to a running mean over $2 \mathrm{~h}$ with $30 \mathrm{~min}$ shift for the continuous time series from the potassium lidar. Otherwise a calculation of temperature is not possible around noon because of high background noise level.

First we concentrate on the nighttime data containing the whole altitude range. In Fig. 2 the temperature deviation from the nightly mean with the regular time resolution of a running mean over $1 \mathrm{~h}$ with $15 \mathrm{~min}$ shift are presented. In all three nights the observed wave pattern is dominated by only few waves. Comparing the wave structures of the different nights it is obvious that the temperature variations of the last night seem to be more unstructured than those of the two nights before. Furthermore, in this night the amplitudes are about $25 \%$ smaller than in the first night.

For extracting the details of these differences vertical wavelengths and periods are calculated by wavelet analyses. The mean wavelet spectra of the vertical wavelengths are shown in Fig. 3. Note that the spectra are smoothed to obtain an equidistant resolution concerning the wavelengths. The interpretation of the results of the triangle (the so-called 'cone of influence') is difficult because the amplitudes are underestimated and the resolution is reduced in these areas. Therefore we renounce to use the values in the "cone of influence". These edge effects are generally independent of the chosen parameters in the wavelet analysis, because they depend only on the finite length of the profiles or the time series (Torrence and Compo, 1998).

Comparing the wavelet spectra of the nights the small amplitudes of the last night are noticeable (Fig. 3). In the first night the dominating modes have wavelengths of about $13 \mathrm{~km}$ and $30 \mathrm{~km}$ exist in all altitudes where we are able to 

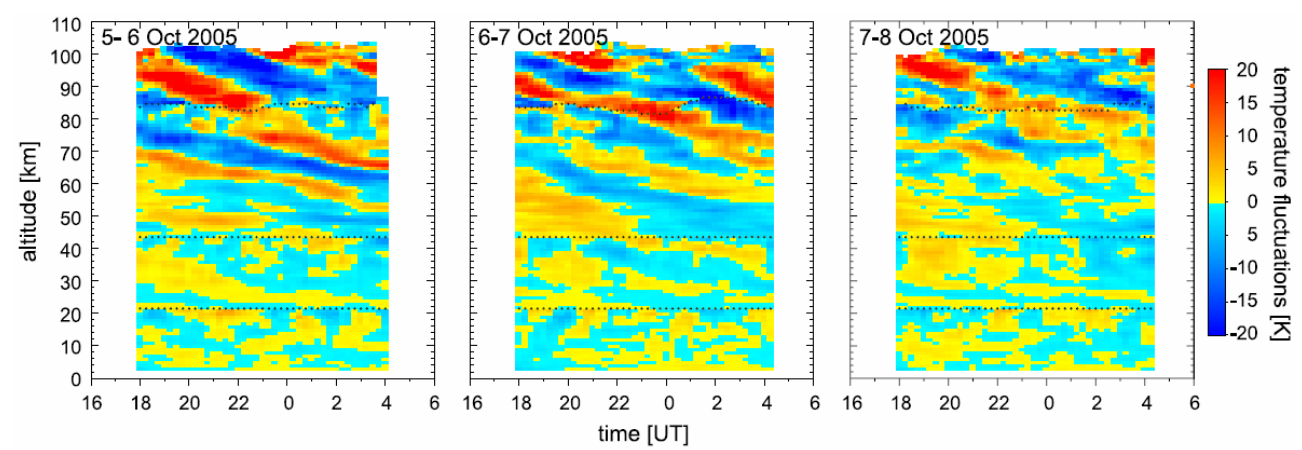

Fig. 2. Temperature deviations from the nightly mean for three consecutive nights (5-8 October 2005). The dotted lines indicate the transition heights between the different measurement methods.

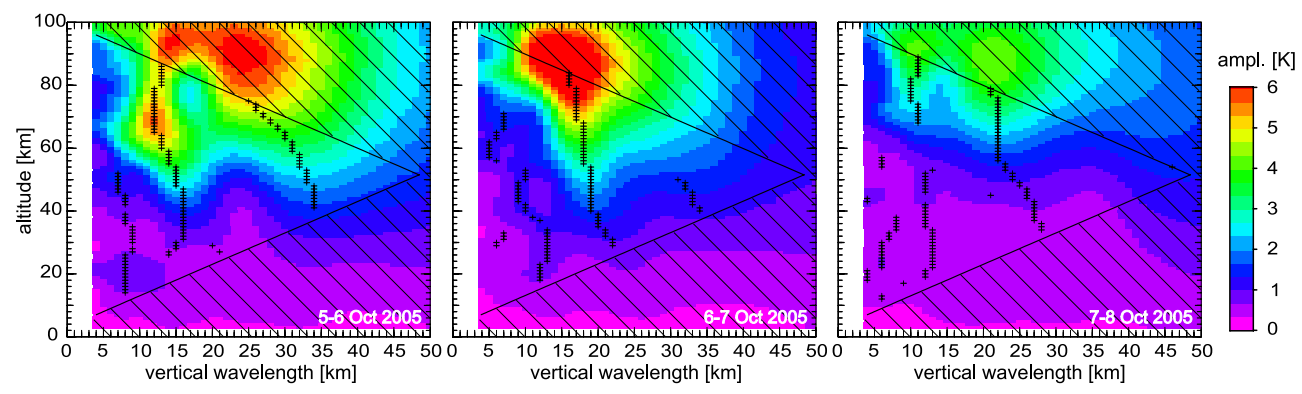

Fig. 3. Mean wavelet spectrum of vertical wavelengths for the temperature profiles shown in Fig. 2 (5-8 October 2005). Pluses indicate the local maxima. The hatched area indicates the 'cone of influence'.

observe them with our measurement and analysing method. In contrast there is only one dominating mode of about $18 \mathrm{~km}$ in the second night. Below $60 \mathrm{~km}$ two other dominating vertical wavelengths of about $35 \mathrm{~km}$ and smaller than $10 \mathrm{~km}$ are also present. In the last night two dominating vertical wavelengths of about $12 \mathrm{~km}$ and $25 \mathrm{~km}$ are found.

The continuous temperature measurements of the potassium lidar in the altitude range $85-95 \mathrm{~km}$ allow to determine periods as well as longer than $6 \mathrm{~h}$. In Fig. 4a the time series of temperature deviations at $90 \mathrm{~km}$ altitude are shown. It has to be noted, that for this analysis the time resolution is reduced to a running mean of $2 \mathrm{~h}$ with $30 \mathrm{~min}$ shift to calculate temperatures also at noon. Variations of about $12 \mathrm{~h}$ are evident in the time series (Fig. 4a). In the results of the wavelet analyses (Fig. 4b) the two first days are dominated by a $12 \mathrm{~h}$ variation with $10-14 \mathrm{~K}$ amplitude, which vanishes in the last night. These variations are indicative of semidiurnal tides. Furthermore, the semidiurnal tide generates about a third or a half of the total fluctuations, which is in agreement with other measurements in mid-latitudes (cp. Shepherd and Fricke-Begemann, 2004). Shorter periodic variations (2-6h), which we interpret in terms of gravity waves, occur intermittently but do not persist more than three hours. The amplitudes of this shorter variations are lower than $8 \mathrm{~K}$.
Combining the different spectral analyses the semidiurnal tide seems to appear with a vertical wavelength of $30-35 \mathrm{~km}$, because this dominating mode of vertical wavelength is the only one which is not present in the third night. In this night the semidiurnal tide is not visible in the period analysis. Simultaneously, in the absence of the semidiurnal tide the wave structures are more chaotic, which were also seen by FrickeBegemann and Höffner (2005).

As shown before the tides influence largely the temperature fluctuations. Furthermore, the maximum duration for nighttime observations in summer are restricted due the shorter nighttime conditions. In Rauthe et al. (2006) examples for winter and summer are described and the influences of the measurement duration are studied. For these reasons the lidar measurements are restricted to a duration of $3-5 \mathrm{~h}$ in the following seasonal examinations in the Sects. 3.2 and 3.3. Due to the restriction we assume that the observed variations are mainly generated by gravity waves.

\section{Seasonal gravity wave activity}

The seasonal variation of the gravity wave parameters as observed by the combination of two lidars above Kühlungsborn are shown in the following paragraphs. As presented in the 
Table 1. Number of measurements longer than $3 \mathrm{~h}$ per year and month. Data before June 2002 and after October 2006 are not included in this paper.

\begin{tabular}{ccccrrrrrrrrrr}
\hline year & J & F & M & A & M & J & J & A & S & O & N & D & $\Sigma$ \\
\hline 2002 & - & - & - & - & - & 1 & 0 & 1 & 2 & 0 & 2 & 2 & 8 \\
2003 & 0 & 5 & 0 & 4 & 1 & 5 & 1 & 7 & 7 & 8 & 2 & 3 & 43 \\
2004 & 1 & 6 & 3 & 8 & 7 & 4 & 6 & 10 & 7 & 9 & 2 & 1 & 64 \\
2005 & 3 & 3 & 7 & 11 & 2 & 10 & 5 & 7 & 7 & 10 & 2 & 1 & 68 \\
2006 & 8 & 1 & 2 & 0 & 6 & 8 & 16 & 1 & 10 & 1 & - & - & 53 \\
\hline$\Sigma$ & 12 & 15 & 12 & 23 & 16 & 28 & 28 & 26 & 33 & 28 & 8 & 7 & 236 \\
\hline
\end{tabular}

previous section the observed wave patterns are dominated by only few waves. Their mean characteristics regarding amplitudes, potential energies and vertical wavelengths are presented here. This analysis includes 236 nights between June 2002 and October 2006 with a minimum duration of $3 \mathrm{~h}$. The different seasons winter (November-January), spring (February-May), summer (June-July) and autumn (AugustOctober) are represented by 27, 66, 56, and 87 measurements, respectively. The distribution throughout the different years and month is listed in Table 1. Apart from some gaps in winter due to adverse weather conditions, the observations are well distributed throughout the year and allow to study the seasonal behaviour.

\subsection{Vertical wavelengths}

Due to the large altitude range covered by the observations the analysis of the vertical wavelengths is very effective. As described in the preceding section one dominating vertical wavelength at each altitude is derived from the nightly mean wavelet spectrum. In Fig. 5a this dominating vertical wavelength is shown at the altitude of $50 \mathrm{~km}$, in which the largest range of vertical wavelengths can be resolved. The crosses represent the results of the single nights. Independent of season the dominating modes found are between 6 and $48 \mathrm{~km}$, i.e. they cover nearly the entire range accessible for our measurement. The mean vertical wavelength is about $20 \mathrm{~km}$ (cf. monthly means in red).

Due to the large day-to-day variability the dependence of vertical wavelengths on altitude is studied on the basis of monthly mean values. No seasonal variation is found at any altitude (cf. Fig. 5b), even though a seasonal dependence would be expected. From the dispersion relation the following approximation can be derived for medium-frequency waves (e.g. Fritts and Alexander, 2003):

$\lambda_{z}=2 \pi \frac{(c-u)}{N}$

with $c$ the ground based phase speed, $u$ the horizontal wind speed and $N$ the Brunt-Väisälä frequency. Note that all parameters of the equation depend on the season. Unfortunately, the values of $c$ (for single waves) and $u$ can not be
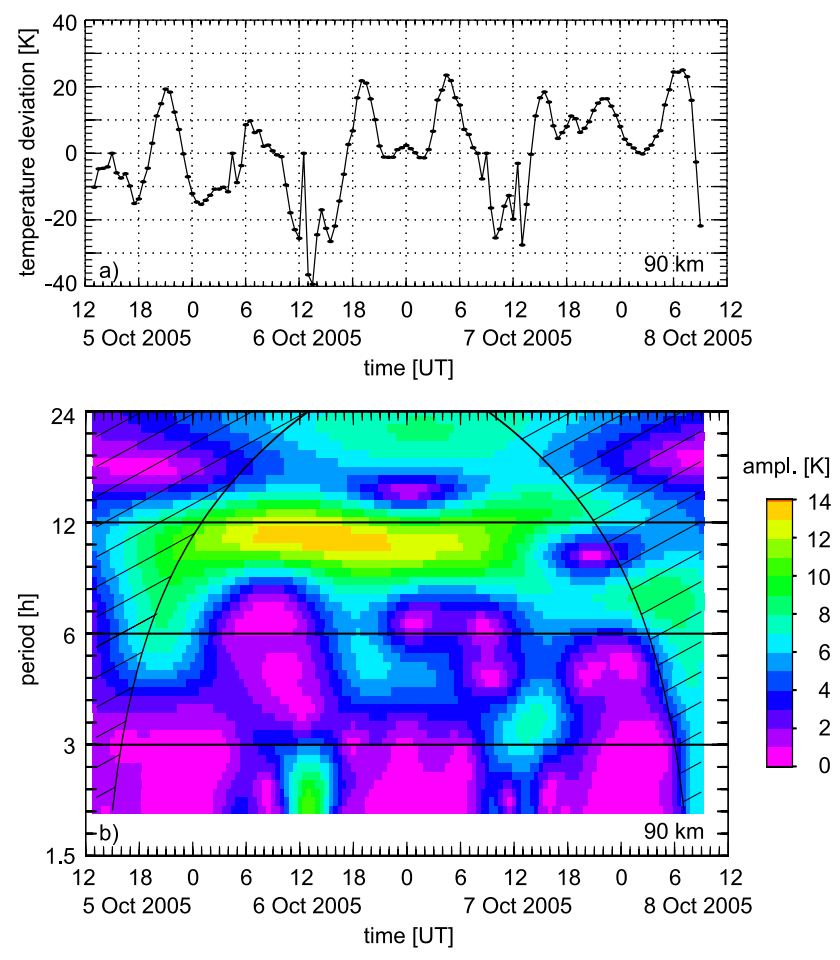

Fig. 4. Measurements of the potassium lidar (5-8 Oct 2005) at $90 \mathrm{~km}$ altitude using a running mean over $2 \mathrm{~h}$ with $30 \mathrm{~min}$ shift in time: (a) Time series of temperature deviations from the nightly mean. (b) Wavelet analyses of periods. The hatched area indicates the 'cone of influence'. Note the non linear $y$-axis.

measured by the lidar. So we can only investigate the dependence on $N$, which is a simplification, because in the middle atmosphere the wind speeds can reach up to $60 \mathrm{~m} / \mathrm{s}$ or more corresponding to a shift in vertical wavelength of roughly $20 \mathrm{~km}$. Nevertheless, since $N$ is up to $25 \%$ smaller in summer than in winter, it would be expected that $\lambda_{z}$ is larger in summer than in winter, what is not observed. But the differences between theory and observations are not surprising because of the influence of the background winds, but this 

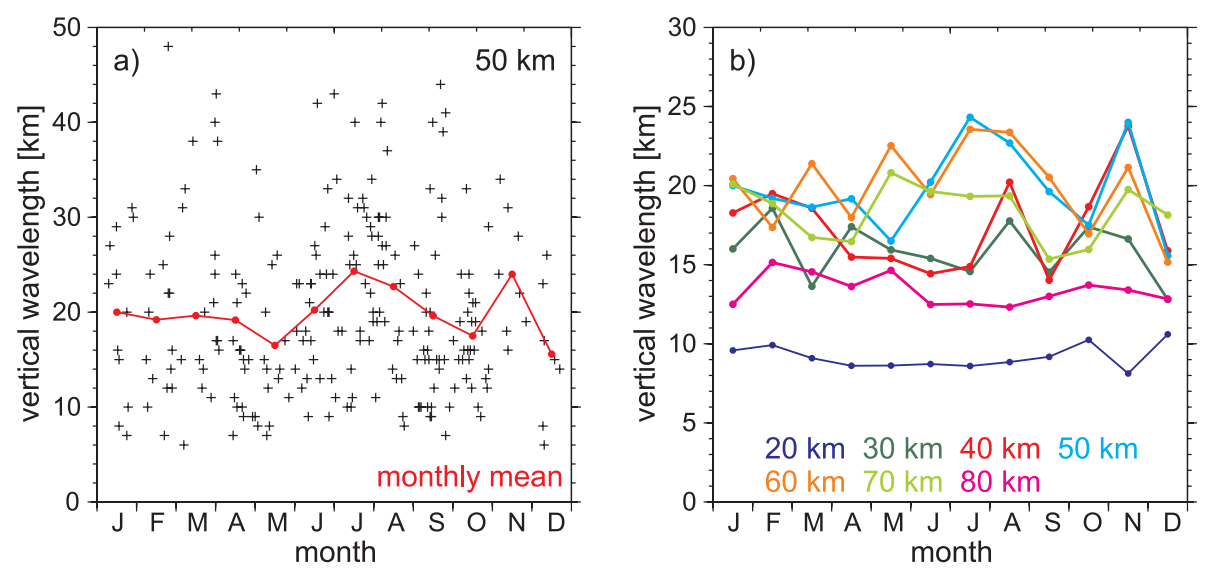

Fig. 5. Dominating vertical wavelengths: (a) Results for a single altitude at $50 \mathrm{~km}$. The black crosses indicate the results of single measurements. The red line and dots show the monthly mean. (b) Results for different altitudes as monthly means. Note the different y-axes.

effect can not be easily quantified. Other theoretical studies predict also a seasonal dependence of vertical wavelengths (e.g. Fritts and VanZandt, 1993). A reason for the absence of seasonal dependence in our observations may be the influence of tides which have vertical wavelengths longer than $25 \mathrm{~km}$.

What we found in Fig. 5 however is that smaller vertical wavelengths $\left(\lambda_{z}<25 \mathrm{~km}\right)$ are more frequent than larger vertical wavelengths (for winter and summer cp. Fig. 8 of Rauthe et al., 2006). The distributions of dominating vertical wavelengths for spring and autumn are similar (not shown). It is likely that the small vertical wavelengths are typical for internal gravity waves, whereas large vertical wavelengths can also be caused by tides. Since due to the limitation of nighttime data it is unfortunately not possible to clearly separate between gravity waves and tides.

The interpretation of the altitude dependence in Fig. 5b is difficult because at the upper and lower edge of the observed altitude range the wavelet analysis does not resolve the largest vertical wavelengths due to the edge effects (e.g. Fig. 3 and explanation in Sect. 2.3). Only altitudes which have the same distance to the edge of the observed altitude range are comparable, i.e. 20 with $80 \mathrm{~km}, 30$ with $70 \mathrm{~km}$ or 40 with $60 \mathrm{~km}$. It seems that the mean vertical wavelengths increase with altitude. To investigate this result a relation from the linear theory is used, which is valid under the Boussinesq approximation (cp. Gardner et al., 1993, Tab. 3):

$\lambda_{z}^{\star}=\lambda_{z, 0}^{\star} \exp \left(\frac{z}{H(q+s)}\right)$.

The dominating vertical wavelength $\left(\lambda_{z}^{\star}\right)$ is defined as vertical wavelength of the largest scale saturated wave. This value depends on the dominating vertical wavelength in a start level $\left(\lambda_{z, 0}^{\star}\right)$, the scale height $(H=7 \mathrm{~km})$, the exponent of the saturated part of the spectrum $(q=3)$ and the expo- nent of the unsaturated part of the spectrum $(s=2)$. Generally, the observed increase is confirmed. But at an altitude of $20 \mathrm{~km}$ our observed dominating mode is about $10 \mathrm{~km}$ and the calculated increase towards $80 \mathrm{~km}$ is much smaller than expected. While we observe an increase of only about $4 \mathrm{~km}$, the increase expected from Eq. 3 would have been more than $10 \mathrm{~km}$. This result indicates also that the background winds influence the dominating vertical wavelengths.

The amplitudes of the dominating vertical wavelengths can also be derived from wavelet spectra (not shown). In contrast to the vertical wavelengths the amplitudes display a clear annual cycle with maximum in winter in all altitudes between 30 and $80 \mathrm{~km}$. Furthermore, the amplitudes of the dominating modes increase with altitude from about $1 \mathrm{~K}$ at $25 \mathrm{~km}$ up to $2.5 \mathrm{~K}(4.5 \mathrm{~K})$ at $80 \mathrm{~km}$ in summer (winter). These results agree with the temperature fluctuations calculated from all waves, which will be presented in the next paragraph.

\subsection{Temperature fluctuations}

The nightly mean temperature fluctuations of the whole year and in the altitude range between 20 and $100 \mathrm{~km}$ are shown in Fig. 6. Note that the values are listed in Table 2. For the first time this gravity wave activity is analysed from lidar measurements in such a large altitude range. As indicated above the data evaluation is limited to durations of $3-5 \mathrm{~h}$ to get a comparable data set in all seasons. We use the first 3 up to $5 \mathrm{~h}$ of our measurements including the whole altitude range. Because of the different start times of the measurements due to weather and seasonal restrictions the selected parts of the measurements have different local times every night. For this reason we avoid systematic errors due to the selection. A more detailed analysis of the influence of the measurement duration on the amplitude can be found in Rauthe et al. 


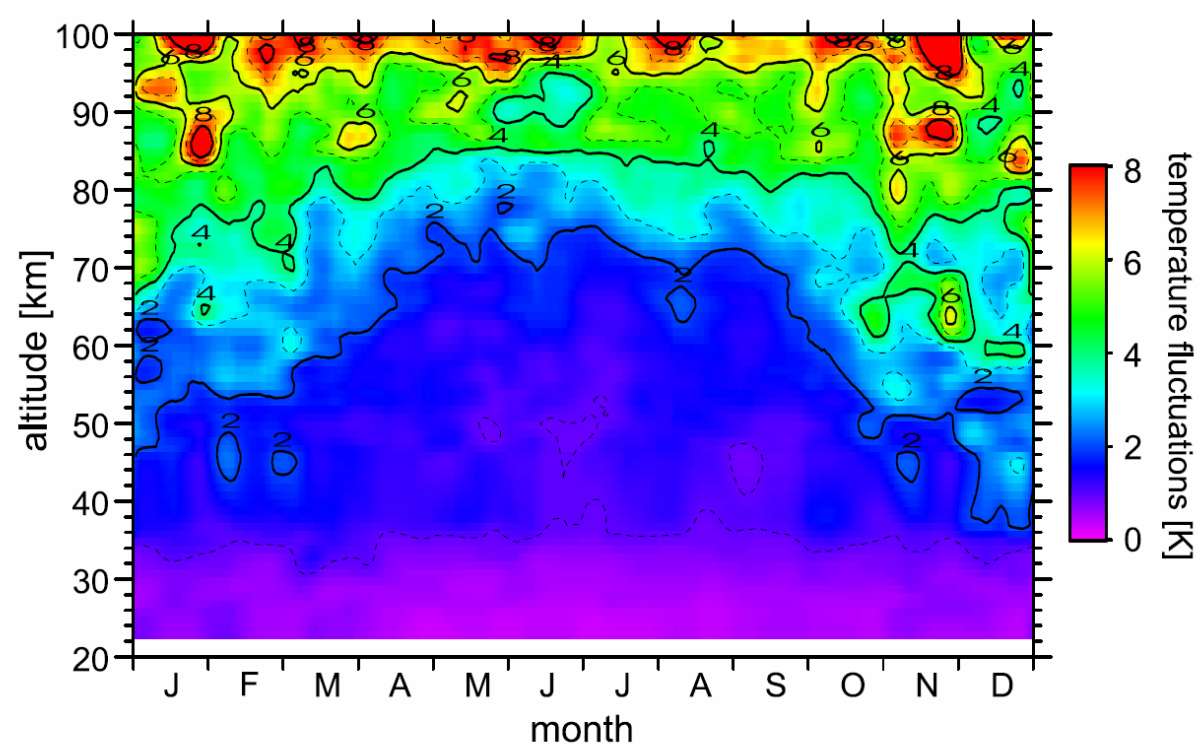

Fig. 6. Seasonal variation of nightly mean temperature fluctuations between 20 and $100 \mathrm{~km}$, i.e. the gravity wave activity. 236 measurements are used and the duration of the single measurements is restricted to intervals of $3-5 \mathrm{~h}$. The data are smoothed with a Hanning filter of $\pm 15 \mathrm{~d}$ and $\pm 2 \mathrm{~km}$.

(2006). However, we would like to point out that a large part of the tidal contribution is eliminated in the resulting temperature fluctuations.

To underline the general gravity wave variation the data in Fig. 6 are smoothed applying a Hanning filter of $\pm 15 d$ and $\pm 2 \mathrm{~km}$. Generally, the temperature fluctuations increase with height from about $0.5 \mathrm{~K}$ at $25 \mathrm{~km}$ up to about $8 \mathrm{~K}$ at $95 \mathrm{~km}$. This behaviour is expected due to the decreasing air density. But the growth rate of the fluctuations with altitude varies throughout the year. Between 35 and $70 \mathrm{~km}$ altitude the increase is weaker in summer than in winter. But between 70 and $90 \mathrm{~km}$ the fluctuations grow faster in summer than in winter. This difference results in an annual variation of temperature fluctuations between 35 and $90 \mathrm{~km}$ altitude than are clearly seen in Fig. 6 . The fluctuations in winter are up to 2.5 times larger than in summer.

\subsection{Potential energy}

As described before the largest seasonal differences of the gravity activity appear between winter and summer. To extract these seasonal differences the seasonal values of the potential energy per volume are calculated and shown in Fig. 7 (note the logarithmic scale). The largest values of potential energy arise in winter and the smallest in summer. The values in autumn and spring are very similar and they are inbetween the values of summer and winter. If the potential energy per volume is constant with height this gives an indication of undamped wave propagation. Nearly undamped propagation is only found below $40 \mathrm{~km}$ in summer and autumn in our observations. Furthermore, the weakest damping occurs in the summer mesosphere $(60-85 \mathrm{~km})$. A more detailed analysis of damping layers in winter and summer can be found in Rauthe et al. (2006). The large variations of the potential energy with height in winter may be a result of the small number of measurements in this season. However, the frequent occurrence of inversion layers in winter blocking gravity waves may produce the observed altitudinal variation of potential energy. Altogether our measurements show despite of only few exceptions a strong decrease of the potential energy with altitude which indicates dissipation throughout the entire middle atmosphere.

\section{Planetary and gravity wave activity}

For more detailed analyses of the different types of wave activity the standard deviations of the monthly mean temperatures and temperature fluctuations are used, i.e. the planetary wave activtiy is compared with the gravity wave activity. Moreover, the transition between the strong gravity wave activity in winter and the weaker activity in summer is studied.

The standard deviations of the monthly mean of the nightly mean temperatures are displayed in Fig. 8. These values show the long-periodic variations of the temperature field due to the large scale atmospheric changes, i.e. the planetary wave activity. Throughout the year the planetary wave activity in the troposphere is large due to the changing weather with high and low pressure systems. Note that the planetary wave activity is slightly larger in winter than in summer. Furthermore, the variability in the stratosphere and lower mesosphere between November and February is relatively high, 
Table 2. Monthly mean temperatures fluctuations (K) between 20 and $100 \mathrm{~km}$ from all soundings longer than $3 \mathrm{~h}$ as shown in Fig. 6

\begin{tabular}{|c|c|c|c|c|c|c|c|c|c|c|c|c|}
\hline $\begin{array}{r}\text { altitude } \\
(\mathrm{km})\end{array}$ & Jan & Feb & Mar & Apr & May & Jun & Jul & Aug & Sep & Oct & Nov & Dec \\
\hline 20 & 0.7 & 0.8 & 0.6 & 0.5 & 0.4 & 0.4 & 0.3 & 0.4 & 0.5 & 0.5 & 0.6 & 0.5 \\
\hline 22 & 0.7 & 0.7 & 0.6 & 0.5 & 0.4 & 0.4 & 0.4 & 0.4 & 0.5 & 0.5 & 0.6 & 0.6 \\
\hline 24 & 0.7 & 0.7 & 0.6 & 0.5 & 0.5 & 0.4 & 0.4 & 0.4 & 0.5 & 0.5 & 0.6 & 0.6 \\
\hline 26 & 0.8 & 0.7 & 0.6 & 0.6 & 0.5 & 0.5 & 0.4 & 0.4 & 0.6 & 0.5 & 0.6 & 0.6 \\
\hline 28 & 0.8 & 0.7 & 0.6 & 0.6 & 0.5 & 0.5 & 0.5 & 0.5 & 0.6 & 0.6 & 0.7 & 0.7 \\
\hline 30 & 0.8 & 0.7 & 0.7 & 0.7 & 0.6 & 0.6 & 0.6 & 0.6 & 0.7 & 0.7 & 0.7 & 0.8 \\
\hline 32 & 0.9 & 0.9 & 0.9 & 0.8 & 0.7 & 0.7 & 0.7 & 0.7 & 0.7 & 0.8 & 0.8 & 0.9 \\
\hline 34 & 1.1 & 1.1 & 1.0 & 1.0 & 0.8 & 0.8 & 0.8 & 0.8 & 0.9 & 1.0 & 1.0 & 1.2 \\
\hline 36 & 1.3 & 1.3 & 1.2 & 1.1 & 1.0 & 1.0 & 1.0 & 1.0 & 1.0 & 1.2 & 1.1 & 1.5 \\
\hline 38 & 1.4 & 1.4 & 1.3 & 1.2 & 1.2 & 1.1 & 1.1 & 1.1 & 1.0 & 1.4 & 1.3 & 1.8 \\
\hline 40 & 1.5 & 1.6 & 1.4 & 1.3 & 1.3 & 1.2 & 1.1 & 1.2 & 1.1 & 1.5 & 1.5 & 2.1 \\
\hline 42 & 1.6 & 1.7 & 1.5 & 1.3 & 1.3 & 1.1 & 1.2 & 1.2 & 1.0 & 1.5 & 1.6 & 2.2 \\
\hline 44 & 1.6 & 1.8 & 1.5 & 1.3 & 1.3 & 1.1 & 1.2 & 1.2 & 1.0 & 1.4 & 1.7 & 2.3 \\
\hline 46 & 1.7 & 1.9 & 1.5 & 1.3 & 1.3 & 1.1 & 1.3 & 1.3 & 1.0 & 1.5 & 1.6 & 2.4 \\
\hline 48 & 1.8 & 1.9 & 1.5 & 1.3 & 1.3 & 1.1 & 1.3 & 1.3 & 1.1 & 1.6 & 1.6 & 2.6 \\
\hline 50 & 1.8 & 1.9 & 1.4 & 1.3 & 1.3 & 1.1 & 1.2 & 1.4 & 1.2 & 1.7 & 1.8 & 2.6 \\
\hline 52 & 1.9 & 1.9 & 1.5 & 1.4 & 1.3 & 1.2 & 1.2 & 1.4 & 1.3 & 1.7 & 2.3 & 2.5 \\
\hline 54 & 2.1 & 2.1 & 1.6 & 1.5 & 1.3 & 1.3 & 1.2 & 1.5 & 1.5 & 1.8 & 2.6 & 2.6 \\
\hline 56 & 2.2 & 2.4 & 1.8 & 1.4 & 1.3 & 1.3 & 1.2 & 1.5 & 1.5 & 2.0 & 2.6 & 3.2 \\
\hline 58 & 2.2 & 2.5 & 1.9 & 1.4 & 1.3 & 1.3 & 1.2 & 1.6 & 1.5 & 2.2 & 2.5 & 3.7 \\
\hline 60 & 2.2 & 2.6 & 2.1 & 1.4 & 1.4 & 1.4 & 1.3 & 1.6 & 1.5 & 2.4 & 2.7 & 3.9 \\
\hline 62 & 2.4 & 2.9 & 2.1 & 1.6 & 1.4 & 1.5 & 1.3 & 1.7 & 1.5 & 2.7 & 3.0 & 3.7 \\
\hline 64 & 2.9 & 3.2 & 2.2 & 1.8 & 1.4 & 1.6 & 1.4 & 1.8 & 1.6 & 2.9 & 3.3 & 3.4 \\
\hline 66 & 3.1 & 3.4 & 2.4 & $\begin{array}{l}1.9 \\
\end{array}$ & 1.5 & 1.8 & 1.5 & 1.8 & 1.7 & 2.9 & 3.8 & 3.2 \\
\hline 68 & 3.3 & 3.7 & 2.7 & 1.9 & 1.7 & $\begin{array}{l}1.0 \\
1.8\end{array}$ & 1.6 & $\begin{array}{l}1.0 \\
1.9\end{array}$ & 1.8 & 2.9 & 4.1 & 3.0 \\
\hline 70 & 3.7 & 4.0 & 3.0 & 2.0 & 1.8 & 1.9 & 1.7 & 2.0 & 2.0 & 2.8 & 4.0 & 2.9 \\
\hline 72 & 4.1 & 3.9 & 3.2 & 2.3 & 1.9 & 2.1 & 1.9 & & 2.3 & & 3.8 & 3.0 \\
\hline 74 & 4.2 & 4.0 & 3.4 & 2.6 & 2.1 & 2.3 & 2.3 & 2.8 & 2.7 & 3.0 & 4.1 & 3.5 \\
\hline 76 & 4.2 & 4.3 & 3.4 & 2.8 & 2.3 & 2.5 & 2.7 & 3.1 & 3.0 & 3.3 & 4.5 & 3.9 \\
\hline 78 & 4.4 & 4.7 & 3.7 & 3.2 & 2.6 & 2.8 & 3.0 & 3.3 & 3.4 & 3.6 & 4.9 & 4.2 \\
\hline 80 & 4.7 & 5.0 & 4.1 & 3.7 & 3.0 & 3.2 & 3.3 & 3.5 & 3.8 & 3.9 & 5.3 & 4.7 \\
\hline 82 & 5.3 & 5.0 & 4.6 & 4.3 & 3.3 & 3.5 & 3.6 & & 4.2 & 4.4 & 5.6 & 5.4 \\
\hline 84 & 6.0 & 5.2 & $\begin{array}{l}4.0 \\
5.1\end{array}$ & 4.8 & 3.7 & 4.0 & $\begin{array}{l}4.0 \\
4.2\end{array}$ & $\begin{array}{l}4.0 \\
4.2\end{array}$ & 4.7 & $\begin{array}{l}4.4 \\
4.9\end{array}$ & 6.2 & 5.7 \\
\hline 86 & 6.3 & 5.5 & 5.5 & 5.0 & 4.2 & 4.4 & 4.9 & 4.6 & 4.9 & 5.3 & 6.8 & 5.3 \\
\hline 88 & 6.1 & 5.9 & 5.8 & 5.1 & 4.8 & 4.5 & 5.3 & 4.9 & 5.0 & 5.4 & 7.0 & 5.1 \\
\hline 90 & 6.0 & 6.2 & 6.1 & 5.0 & 5.3 & 4.5 & 5.2 & 5.1 & 4.9 & 5.3 & 6.5 & 5.3 \\
\hline 92 & 6.1 & 6.5 & 6.2 & 5.0 & 5.6 & 4.5 & 5.2 & 5.2 & 4.9 & 5.3 & 6.2 & 5.6 \\
\hline 94 & 6.3 & 7.2 & 6.2 & 5.3 & 5.9 & 4.8 & 5.7 & 5.5 & 5.3 & 5.5 & 6.4 & 5.9 \\
\hline 96 & 6.5 & 7.9 & 6.4 & 5.7 & 6.5 & 5.6 & 6.3 & 6.1 & 5.9 & 6.1 & 7.2 & 6.1 \\
\hline 98 & 7.4 & 8.1 & 6.9 & 6.4 & 7.0 & 6.7 & 6.4 & 6.9 & 6.4 & 6.9 & 7.8 & 6.1 \\
\hline 100 & 8.2 & 7.9 & 7.2 & 7.0 & 7.0 & 7.4 & 6.5 & 7.6 & 6.6 & 7.6 & 8.1 & 6.5 \\
\hline
\end{tabular}

especially in December and January, which is due to the displacement of the polar vortex and the resulting favourable propagation conditions for planetary waves. In April and September the transition between the high winter mesopause and the lower summer mesopause is marked by a large temperature variability. Between May and August the variability of the temperatures is low, which means that the planetary wave activity is weak, especially between 10 and $70 \mathrm{~km}$.

The monthly mean temperature fluctuations and their standard deviations are shown in Fig. 9. As described in Sect. 3.2 the largest seasonal differences between the monthly mean temperature fluctuations can be found between 40 and $70 \mathrm{~km}$ (cp. also Fig. 6). Furthermore, the variability of the monthly means (indicated by the bars) below $80 \mathrm{~km}$ is much smaller in summer than in winter. In further studies, which will be published in a separate paper, we will show that during so called stratospheric warmings and associated mesospheric coolings the gravity wave activity is smaller than for mean winter conditions. The total variability of the gravity wave activity increases in the winter stratopause region and also in the lower mesosphere (cp. bars in Fig. 9). Above $80 \mathrm{~km}$ the variability is too high to identify seasonal differences (cp. also Fig. 6). In contrast to the temperatures and the planetary wave activ-

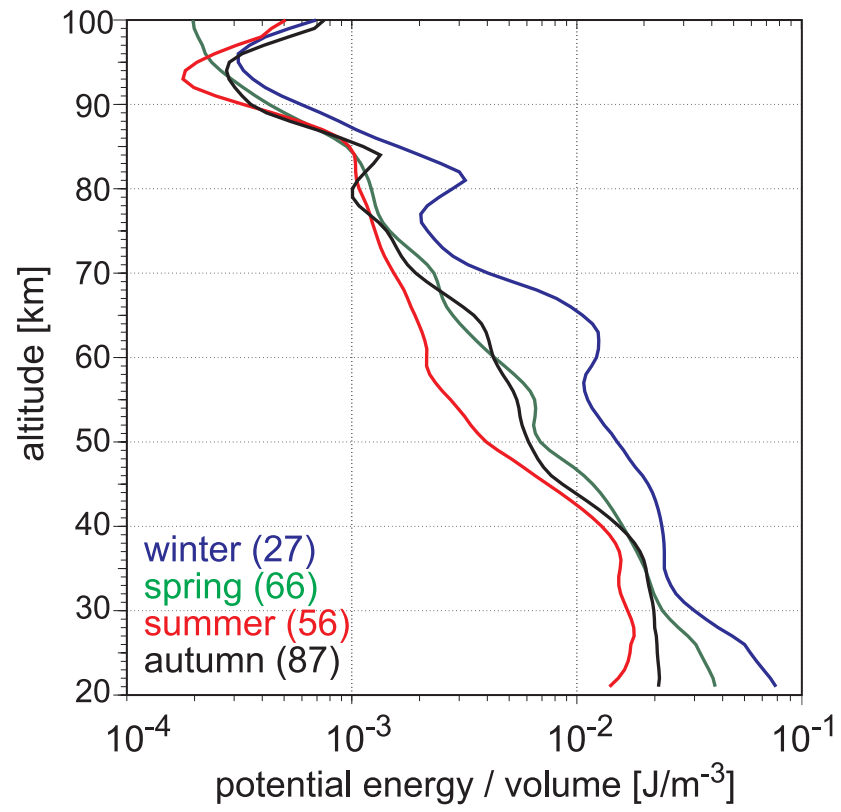

Fig. 7. Profiles of potential energy per volume for different altitudes. A Hanning filter of $\pm 5 \mathrm{~km}$ is used to smooth the data. Note the logarithmic scale of the $\mathrm{x}$-axis.

ity the temperature fluctuations (i.e. the gravity wave activity) show typical summer characteristics between March and September and not only between May and August, i.e. the fluctuations increase only slowly up to $70 \mathrm{~km}$.

Combining the variability of the monthly mean temperatures and the temperature fluctuations allows a comparison between the large scale wave activity, which is mainly caused by planetary waves, and the small scale wave activity caused by gravity waves. In our observations the planetary wave activity and the gravity wave activity show similar structures with season and altitude. Only below $35 \mathrm{~km}$ the gravity wave activity is very low throughout the year and the planetary wave activity is large in winter due to the changes in the polar vortex. In the winter stratosphere and mesosphere stratospheric warmings modify the planetary and gravity wave activity. The observations show a larger planetary wave activity and an increased variability of the gravity wave activity, especially in the lower mesosphere. The wave activity is large in the upper mesosphere throughout the year due to the general growth of the wave amplitude with altitude. Furthermore, the total variability increases due to inversion layers between 70 and $80 \mathrm{~km}$ (cp. Gerding et al., 2008). In summary, the observations show that the change of planetary wave activity accompanies a change in the gravity wave activity and vice versa. Impressive examples of this coupling are stratospheric warming events which lead to an increase in the planetary wave activity and a decrease of the gravity wave activity due to the stronger filtering. We suggest that these similarities between the different scales are due to the background fields, 


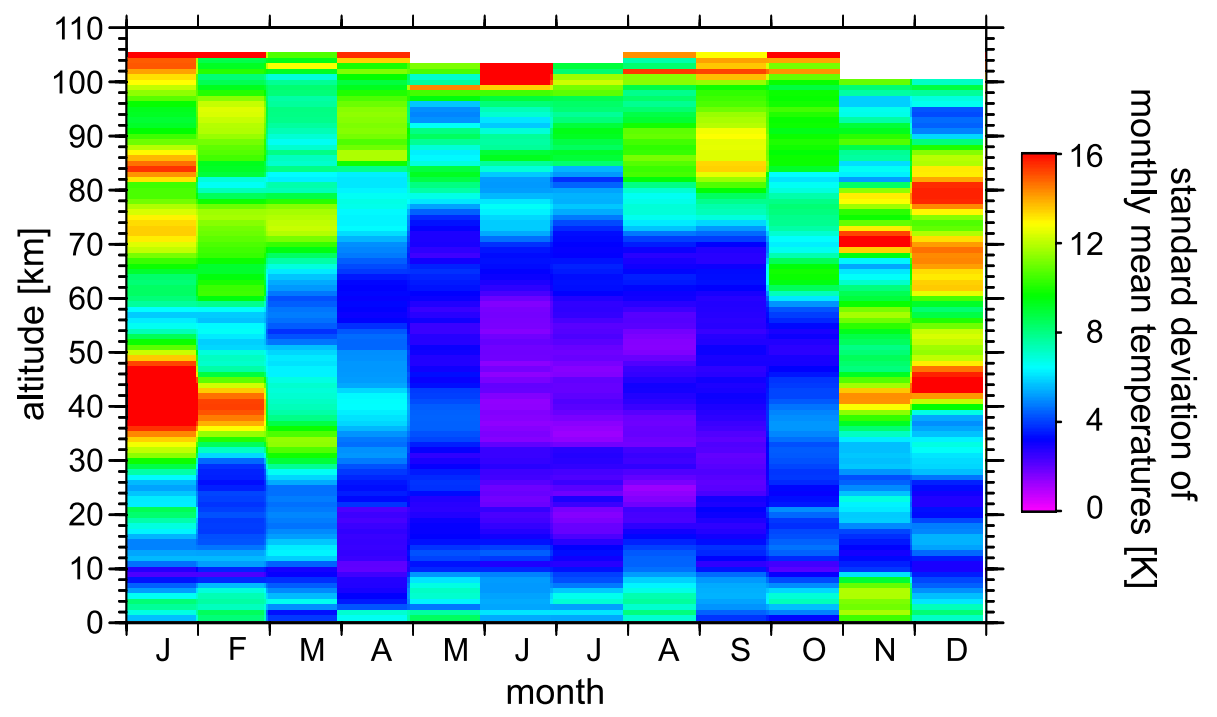

Fig. 8. Standard deviation of the monthly mean temperatures between 0 and $105 \mathrm{~km}$ characterising the planetary wave activity. 236 measurements are used.
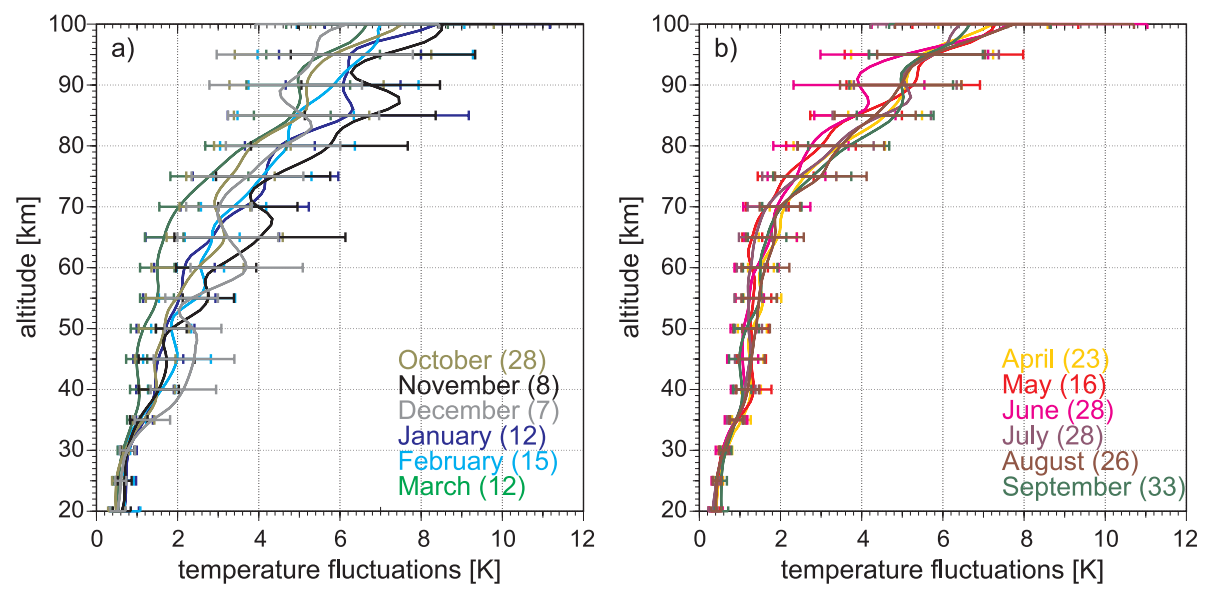

Fig. 9. Monthly mean temperature fluctuations for (a) October-March and (b) April-September characterising the gravity wave activity. The numbers indicate the number of measurements per month. The bars show the standard deviation. A Hanning filter of $\pm 5 \mathrm{~km}$ is used to smooth the data.

i.e. the temperature changes due to waves which imply also changes in the wind field and vice versa. The filtering and damping of waves of all scales are also modified.

To characterise the different seasons we shortly describe the absolute temperatures, which are published in Gerding et al. (2008), Figs. 3 and 4. In the winter stratopause region high temperatures of more than $300 \mathrm{~K}$ in a single night are found in our observations due to so called stratospheric warming events. Altogether the mean stratopause temperatures are in summer slightly higher than in winter. The so called two-level mesopause structure (She and von Zahn, 1998) is identifiable in our measurements, but because of the variable extension of the metal layer from night to night, the higher winter-level $(\sim 103 \mathrm{~km})$ of the mesopause is not always detectable. However, for the months between May and August the lower and extremely cold mesopause at about $86 \mathrm{~km}$ is clearly visible. The mesopause temperature reaches about $140 \mathrm{~K}$ in June and July while it is about $12 \mathrm{~K}$ warmer in May and August.

Combining the results of the absolute temperatures (Fig. 4 of Gerding et al., 2008) and the temperature fluctuations (Fig. 9) some conclusions about the direction of the transition from summer to winter state are possible. In September and October the temperatures in the mesopause region are 
clearly similar to the winter state, but the fluctuations in the lower mesosphere and upper stratosphere are clearly similar to the summer state. This result indicates that the temperature and its fluctuations change first in the mesopause region and later in the stratopause region. There are some indications for a similar mechanism in spring. This top-down motion in spring and autumn was also observed in the winds (e.g. Hoffmann et al., 2002). It is confirmed by theoretical conceptions as described e.g. by Fritts (2003), in which the wave forcing changes the wind and temperature profiles and this process starts in the mesopause region.

\section{Discussion}

Comparing our results with other measurements it has to be noted that depending on the measurement method different parts of the gravity wave spectrum are resolved. Furthermore, there are no long-term lidar observations which include the whole altitude range from the lower stratosphere up to the lower thermosphere. In the following discussion only lidar measurements in mid-latitudes are used from the RMR lidar in southern France (Haute-Provence, $44^{\circ} \mathrm{N}, 6^{\circ} \mathrm{E}$ and Biscarosse, $44^{\circ} \mathrm{N}, 1^{\circ} \mathrm{W}$ ), in Wales (Aberystwyth, $52^{\circ} \mathrm{N}$, $4^{\circ} \mathrm{E}$ ) and in Canada (Toronto, $44^{\circ} \mathrm{N}, 88^{\circ} \mathrm{E}$ ), and for the mesopause region from the Na lidar in the USA (Urbana, $40^{\circ} \mathrm{N}, 88^{\circ} \mathrm{W}$ ). In Urbana there are also RMR lidar measurements. In addition results of satellite and rocket measurements are discussed.

Due to vertical wavelengths all comparable measurements include only a part of the wave spectrum which is covered by our measurements. For this reason the comparison of absolute values is less useful. No indication of a seasonal dependence on vertical wavelengths are found in the lidar measurements of Gardner and Voelz (1987) and Gardner et al. (1989), which is in agreement with our results from the whole altitude range from the troposphere up to the thermosphere. However the data of the CRISTA satellite instrument from August 1997 show a dominating vertical wavelength of $14 \mathrm{~km}$ in $25 \mathrm{~km}$ altitude in winter on the Southern Hemisphere and a $2 \mathrm{~km}$ larger vertical wavelength in the summer of the Northern Hemisphere (Ern et al., 2004). Similar results have also been found for HIRDLS in the altitude range from 20 up to $55 \mathrm{~km}$ (Alexander et al., 2008). But these differences are probably not only caused by seasonal effects but also by hemispheric effects, e.g. different sources of gravity waves.

As shown by our measurements the dominating vertical wavelength increases with altitude as expected by the theory. The slower as expected increase with altitude demonstrates that the mechanisms are more complex and the background winds plays an important role. This result agrees with the bases for most currently used gravity wave parameterisations (Hines, 1997a,b; Alexander and Dunkerton, 1999; Warner and McIntyre, 2001). These concepts were successfully ap- plied to model, for instance, global distributions of gravity wave parameters measured by satellites (Alexander, 1998; Ern et al., 2006; Preusse et al., 2006).

In contrast to the paper of Offermann et al. (2006) there is no indication of a dramatic change in the temperature fluctuations in the upper mesosphere in our data, which also vary with the season. Only between March and September the fluctuations increase up to $70 \mathrm{~km}$ slowly and above strongly. But in the other months the increase of the amplitudes is more or less continuous in our measurements.

Because of the seasonal similarity of the temperature fluctuations and the potential energy both parameters will be discussed together as gravity wave activity in the following. As shown before by Rauthe et al. (2006) there is a clear seasonal variation of the gravity wave activity in midlatitudes with maximum in winter, especially between 35 and $90 \mathrm{~km}$ altitude. This result is in agreement with other lidar measurements and also with data from radiosondes, satellites and rockets. Between 30 and $60 \mathrm{~km}$ all lidar measurements vary annually with maximum values in winter (Gardner et al., 1989; Wilson et al., 1991b; Mitchell et al., 1991; Whiteway and Carswell, 1995). In the data of Wilson et al. (1991b) from France an additional semi-annual component of the gravity wave activity is observed above $60 \mathrm{~km}$. Hence a second maximum in summer occurs, whose reason is not completely understood. They assume that the minima occur during weak mean wind intensity. The two times larger values of gravity wave activity in winter compared to the summer is also measured by the satellite instruments (e.g. Wu and Waters, 1996b; Ern et al., 2004; Alexander et al., 2008) and also by rockets (e.g. Hirota, 1984; Eckermann et al., 1995). An analysis of the SABER data shows also a semi-annual variation (Krebsbach and Preusse, 2007) but in our latitude of $54^{\circ} \mathrm{N}$ the interpretation of the data is problematic because every two months the line of sight of the instrument changes. Only if the instrument is looking northward the latitude of $54^{\circ} \mathrm{N}$ is observed. In the mesopause region and also in the upper troposphere and lower stratosphere the differences between the seasons vanish more and more in all types of measurements (cp. Gardner and Voelz, 1987; Allen and Vincent, 1995; Tsuda et al., 2000; Wang and Geller, 2003; Rauthe et al., 2006).

The cause of the observed annual variation of the gravity wave activity was discussed by different authors. On the one hand the background temperature and density play an important role to explain the winter-summer-differences as shown by Eckermann et al. (1995), Alexander (1998). In our data the winter-summer-ratio of the temperature fluctuation is larger than one like the winter-summer-ratio of these background parameters. Moreover the altitudinal structure agrees roughly in our data (Rauthe et al., 2006). On the other hand the influence of the background wind via filtering is often discussed (e.g. Wilson et al., 1991b; Whiteway and Carswell, 1995). Lindzen (1981) demonstrated this connection of wind and waves, i.e. that the wind filtering of waves is different in 
winter and summer due to the eastward wind and westward wind in the middle atmosphere, respectively. But with our lidar data no statement is possible yet. First the gravity waves observed by a lidar station are not necessarily influenced by the local wind field below because of the tilted propagation of the waves. Second the sources of the gravity waves may be seasonally different. In our present data set we did not find a direct correlation between the strength of the gravity wave activity and the wind direction and/or wind speed taken from ECMWF analyses (not shown). On the one hand we find that if there is a change of the wind direction, i.e. a different filtering, there is no indication for a correlated change in the observed gravity wave activity. On the other hand a large difference between wind maximum and wind minimum in an ECMWF wind profile would imply that more waves should be filtered and the observed gravity wave activity (temperature fluctuations) should be smaller. However, in our lidar observation no correlation between maximum wind differences and observed temperature fluctuations is found. Advanced analyses with ray tracing to determine the sources are necessary and also the combination of the lidar results with wind measurements of radars to determine e.g. the propagation direction of the waves.

One important result of our measurements concerning the gravity wave activity is that damping of waves is observed at nearly all altitudes and in all seasons. Even though this continuous dissipation seems to be natural most global circulation models favour gravity wave parameterisations which deposit their momentum close to regions of strong wind shear based on (Lindzen, 1981). Due to our observations a parameterisation of Warner and McIntyre (2001) seems to be more realistic because of the continuous momentum deposition.

\section{Conclusions and outlook}

In this paper the measurements with two lidars (RMR lidar and potassium lidar) include the whole altitude range from the troposphere up to the lower thermosphere. The presented data set contains more than 230 nights with more than 1700 measurement hours. The data were analysed in terms of waves. As shown by a case study the night-to-night variability is high and depends also on tides. It seems that the presence of the semidiurnal tide produces clearer wave structures. In the whole data set monthly mean values of dominating vertical wavelengths between 10 and $20 \mathrm{~km}$ are observed. Even though diverse theoretical studies suggest a seasonal dependence of vertical wavelengths, no seasonal differences for the dominating vertical wavelengths are found in our data which indicate a multilayered dependence not only on the Brunt-Väisälä frequency as well as on background winds. Unlike the vertical wavelengths the temperature fluctuations and also the potential energy show a strong seasonal variation with maximum values in winter, which are up to 2.5 times larger than in summer. The causes of the annual variations are discussed in a previous paper (Rauthe et al., 2006). It is clear that the background temperature and density explain a main part of the winter-summer-differences of the fluctuations. The differences with season are small below $35 \mathrm{~km}$ and above $90 \mathrm{~km}$. The nightly mean fluctuations increase with altitude from less then $1 \mathrm{~K}$ up to $8 \mathrm{~K}$. Nevertheless, damping of waves occurs nearly in all seasons and altitudes. But the weakest damping in the mesosphere is found in the summer between 60 and $85 \mathrm{~km}$, which is emphasised by the results of the damping layer analysis of Rauthe et al. (2006). Comparing the planetary wave activity with the gravity wave activity the altitudinal structure and also the seasonal structure of the variations are similar. This similarity indicates that both types of activity are coupled, i.e. the different scales depend on the same way on the background fields, e.g. on the wind. In combination with the temperature results (cp. Gerding et al., 2008) we can conclude that the transition between the winter and summer season and vice versa in the temperature and their fluctuations starts in the mesopause region and than continues in the mesosphere and stratosphere, which confirms the theoretical concept of downward-control.

The lidar technique includes the whole altitude range from the troposphere/lower stratosphere up to the lower thermosphere. The main focus of our observations is the middle atmosphere, where propagation, filtering and dissipation occur. We have shown that the large altitude range and the high temporal and spatial resolution allow to study an important part of the wave spectrum and the coupling between the scales and also between the different layers of the atmosphere. Limitations of lidar measurements are that they are only done at a single location and do not bring any information about the wind. A combination with other measurements e.g. from radars is planned to eliminate the deficiencies and to extend and affirm the analyses presented here.

Acknowledgements. We thank Matthias Alpers (now at DLR Bonn) for developing the IAP RMR lidar until autumn 2002 and Josef Höffner for making the potassium lidar data available. Furthermore, we appreciate the support in lidar operation and maintenance of Torsten Köpnick and Michael Priester. In addition, we would like to thank our colleagues at the IAP and numerous students for their help in nighttime lidar soundings. In addition, we are grateful to the two anonymous reviewers to improve the paper with their helpful comments. Parts of this work were supported by the Deutsche Forschungsgemeinschaft under grant GE 1625/1-1.

Edited by: P. Hartogh

\section{References}

Alexander, M. J.: Interpretations of observed climatological patterns in stratospheric gravity wave variance, J. Geophys. Res., 103, 8627-8640, doi:10.1029/97JD03325, 1998.

Alexander, M. J. and Dunkerton, T. J.: A spectral parameterization of mean-flow forcing due to breaking gravity waves, J. Atmos. 
Sci., 56, 4167-4182, doi:10.1175/1520-0469(1999)056〈4167: ASPOMF $>$ 2.0.CO;2, 1999.

Alexander, M. J., Gillw, J., Cavanaugh, C., M, C., Eden, T., Francis, G., Halvorson, C., Hannigan, J., Khosravi, R., Kinnison, D., Lee, H., Massie, S., Nardi, B., Barnett, J., Hepplewhite, C., Lambert, A., and Dean, V.: Global estimates of gravity wave momentum flux from High Resolution Dynamics Limb Sounder observations, J. Geophys. Res., 113, D15S18, doi: 10.1029/2007JD008807, 2008.

Allen, S. J. and Vincent, R. A.: Gravity wave activity in the lower atmosphere: Seasonal and latitudinal variations, J. Geophys. Res., 100, 1327-1350, doi:10.1029/94JD02688, 1995.

Alpers, M., Eixmann, R., Fricke-Begemann, C., Gerding, M., and Höffner, J.: Temperature lidar measurements from 1 to $105 \mathrm{~km}$ altitude using resonance, Rayleigh, and rotational Raman scattering, Atmos. Chem. Phys., 4, 793-800, 2004, http://www.atmos-chem-phys.net/4/793/2004/.

Dao, P. D., Farely, R., Tao, X., and Gardner, C. S.: Lidar observations of the temperature profile between 25 and $105 \mathrm{~km}$ : Evidence of strong tidal perturbations, Geophys. Res. Lett., 22, 2825-2828, doi:10.1029/95GL02950, 1995.

Eckermann, S. D., Hirota, I., and Hocking, W. K.: Gravity wave and equatorial wave morphology of the stratosphere derived from long-term rocket soundings, Quart. J. Roy. Meteorol. Soc., 121, 149-186, doi:10.1256/smsqj.52107, 1995.

Ern, M., Preusse, P., Alexander, M. J., and Warner, C. D.: Absolute values of gravity wave momentum flux derived from satellite data, J. Geophys. Res., 109, D20103, doi:10.1029/ 2004JD004752, 2004.

Ern, M., Preusse, P., and Warner, C.: Some experimental constraints for spectral parameters used in the Warner and McIntyre gravity wave parameterization scheme, Atmos. Chem. Phys., 6, 43614381, 2006, http://www.atmos-chem-phys.net/6/4361/2006/.

Fleming, E. L., Chandra, S., Barnett, J. J., and Corney, M.: Zonal mean temperature, pressure, zonal wind, and geopotential height as functions of latitude, COSPAR international reference atmosphere: 1986, Part II: Middle atmosphere models, Adv. Space Res., 10, 11-59, doi:10.1016/0273-1177(90)90386-E, 1990.

Fricke-Begemann, C. and Höffner, J.: Temperature tides and waves near the mesopause from lidar observations at two latitudes, J. Geophys. Res., 110, D19103, doi:10.1029/2005JD00770, 2005.

Fritts, D. C.: Gravity waves, in: Encyclopedia of Atmospheric Science, edited by: Holton, J. R., Curry, J. A., and Pyle, J. A., Academic Press, San Diego, CA, USA, 1308-1314, 2003.

Fritts, D. C. and Alexander, M. J.: Gravity wave dynamics and effects in the middle atmosphere, Rev. Geophys., 41, 3/1-64, doi: 10.1029/2001RG000106, 2003.

Fritts, D. C. and Hoppe, U.-P.: High-resolution measurements of vertical velocity with the European incoherent scatter VHF radar 2. Spectral observations and model comparisons, J. Geophys. Res., 100, 16 827-16 838, doi:10.1029/95JD01467, 1995.

Fritts, D. C. and VanZandt, T. E.: Spectral estimates of gravity wave evergy and momentum fluxes. Part I: Energy dissipation, acceleration, and constraints., J. Atmos. Sci., 50, 3685-3694, 1993.

Gardner, C. S. and Voelz, D. G.: Lidar studies of the nighttime sodium layer over Urbana, Illinois, 2. Gravity waves, J. Geophys. Res., 92, 4673-4694, 1987.

Gardner, C. S., Miller, M. S., and Liu, C. H.: Rayleigh lidar observations of gravity wave activity in the upper stratosphere at
Urbana, Illinois, J. Atmos. Sci., 46, 1838-1854, doi:10.1175/ 1520-0469(1989)046〈1838:RLOOGW $\rangle$ 2.0.CO;2, 1989.

Gardner, C. S., Hostetler, C. A., and Franke, S. J.: Measurement distortion in aircraft, space shuttle and balloon observations of atmospheric density and temperature perturbation spectra, J. Geophys. Res., 98, 1023-1033, 1993.

Gerding, M., Rauthe, M., and Höffner, J.: Temperature soundings from 1 to $105 \mathrm{~km}$ altitude by combination of co-located lidars, and its application for gravity wave examination, in: Reviewed and revised papers presented at the 22nd International Laser Radar Conference, edited by Pappalardo, G. and Amodeo, A., vol. ESA SP-561, Nordwijk, The Netherlands, 567-570, 2004.

Gerding, M., Höffner, J., Lautenbach, J., Rauthe, M., and Lübken, F.-J.: Seasonal variation of temperatures between 1 and $105 \mathrm{~km}$ altitude at $54^{\circ} \mathrm{N}$ by lidar, Atmos. Chem. Phys. Discuss., 8, 16175-16218, 2008, http://www.atmos-chem-phys-discuss.net/8/16175/2008/.

Hertzog, A., Vial, F., Mechoso, C. R., Basdevant, C., Cocquerez, P., Dubourg, V., and Nouel, F.: Planetary and gravity wave activity in the equatorial lower stratosphere as seen by ultralong duration balloons, Adv. Space Res., 30, 1381-1386, doi: 10.1016/S0273-1177(02)00555-0, 2002.

Hines, C. O.: Doppler-spread parameterization of gravity-wave momentum deposition in the middle atmosphere. Part 1: Basic formulation, J. Atmos. Solar-Terr. Phys., 59, 371-386, 1997a.

Hines, C. O.: Doppler-spread parameterization of gravity-wave momentum deposition in the middle atmosphere. Part 2: Broad and quasi monochromatic spectra, and implementation, J. Atmos. Solar-Terr. Phys., 59, 387-400, 1997 b.

Hirota, I.: Climatology of gravity waves in the middle atmosphere, J. Atmos. Terr. Phys., 46, 767-773, doi:10.1016/0021-9169(84) 90057-6, 1984.

Hoffmann, P., Singer, W., and Keuer, D.: Variability of the mesospheric wind field at middle and Arctic latitudes in winter and its relation to stratospheric circulation disturbances, J. Atmos. Solar-Terr. Phys., 64, 1229-1240, doi:10.1016/S1364-6826(02) 00071-8, 2002.

Holton, J. R.: The role of gravity wave induced drag and diffusion in the momentum budget of the mesosphere, J. Atmos. Sci., 39, 791-799, doi:10.1175/1520-0469(1982)039〈0791:TROGWI $\rangle$. $0 . \mathrm{CO} ; 2,1982$.

Holton, J. R. and Alexander, M. J.: The role of waves in the transport circulation of the middle atmosphere, in: Atmospheric science across the stratopause, edited by Siskind, D. E., Eckermann, S. D., and Summers, M. E., vol. 123 of AGU Monograph Series, American Geophysical Union, Washington DC, USA, 2135, 2000.

Krebsbach, M. and Preusse, P.: Spectral analysis of gravity wave activity in SABER temperature data, Geophys. Res. Lett., 34, L03814, doi:10.1029/2006GL028040, 2007.

Lindzen, R. S.: Turbulence and stress owing to gravity wave and tidal breakdown, J. Geophys. Res., 86, 9707-9714, 1981.

McLandress, C.: On the importance of gravity waves in the middle atmosphere and their parameterization in general circulation models, J. Atmos. Solar-Terr. Phys., 60, 1357-1383, doi: 10.1016/S1364-6826(98)00061-3, 1998.

Mitchell, N. J., Thomas, L., and Marsh, A. K. P.: Lidar observations of long-period gravity waves in the stratosphere, Ann. Geophys., 9, 588-596, 1991, 
http://www.ann-geophys.net/9/588/1991/.

Nakamura, T., Tsuda, T., Fukao, S., Manson, A. H., Meek, C. E., Vincent, R. A., and Reid, I. M.: Mesospheric gravity waves at Saskatoon $\left(52^{\circ} \mathrm{N}\right)$, Kyoto $\left(35^{\circ} \mathrm{N}\right)$, and Adelaide $\left(35^{\circ} \mathrm{S}\right)$, J. Geophys. Res., 101, 7005-7012, doi:10.1029/95JD03826, 1996.

Offermann, D., Jarisch, M., Oberheide, J., Gusev, O., Wohltmann, I., Russell III, J. M., and Mlynczak, M. G.: Global wave activity from upper stratosphere to lower thermosphere: A new turbopause concept, J. Atmos. Solar-Terr. Phys., 68, 1709-1729, doi:10.1016/j.jastp.2006.01.013, 2006.

Preusse, P., Ern, M., Eckermann, S. D., Warner, C. D., Picard, R. H., Knieling, P., Krebsbach, M., Russell III, J. M., Mlynczak, M. G., Mertens, C. J., and Riese, M.: Tropopause to mesopause gravity waves in August: Measurement and modeling, J. Atmos. Solar-Terr. Phys., 68, 1730-1751, doi:10.1016/j.jastp.2005.10. 019, 2006.

Rapp, M., Strelnikov, B., Müllemann, A., Lübken, F.-J., and Fritts, D. C.: Turbulence measurements and implications for gravity wave dissipation during the MaCWAVE/MIDAS rocket program, Geophys. Res. Lett., 31, L24S07, doi:10.1029/2003GL019325, 2004.

Rauthe, M., Gerding, M., Höffner, J., and Lübken, F.-J.: Lidar temperature measurements of gravity waves over Kühlungsborn $\left(54^{\circ} \mathrm{N}\right)$ from 1 to $105 \mathrm{~km}$ : A winter-summer comparison, J. Geophys. Res., 111, D24108, doi:10.1029/2006JD007354, 2006.

Schöch, A., Baumgarten, G., Fritts, D. C., Hoffmann, P., Serafimovich, A., Wang, L., Dalin, P., Müllemann, A., and Schmidlin, F. J.: Gravity waves in the troposphere and stratosphere during the MaCWAVE/MIDAS summer rocket program, Geophys. Res. Lett., 31, L24S04, doi:10.1029/2004GL019837, 2004.

Serafimovich, A., Hoffmann, P., Peters, D., and Lehmann, V.: Investigation of intertia-gravity waves in the upper troposphere/lower stratosphere over Northern Germany observed with collocated VHF/UHF radars, Atmos. Chem. Phys., 5, 295-310, 2005, http://www.atmos-chem-phys.net/5/295/2005/.

She, C. Y. and von Zahn, U.: Concept of a two-level mesopause: Support through new lidar observations, J. Geophys. Res., 103, 5855-5863, doi:10.1029/97JD03450, 1998.

Shepherd, M. and Fricke-Begemann, C.: Study of tidal variations in mesospheric temperature at low and mid latitudes from WINDII and potassium lidar observations, Ann. Geophys., 22, 15131528, 2004, http://www.ann-geophys.net/22/1513/2004/.

Sica, R. J., Sargoytchev, S., Argall, P. S., Borra, E. F., and Girard, L.: Lidar measurements taken with a large-aperture liquid mirror: 1. Rayleigh-scatter system, Appl. Opt., 34, 6925-6936, 1995.

Sofieva, V. F., Kyrölä, E., Hassinen, S., Backman, L., Tamminen, J., Seppälä, A., Thölix, L., Gurvich, A. S., Kan, V., Dalaudier, F., Hauchecorne, A., Bertaux, J.-L., Fussen, D., Vanhellemont, F., Fanton d'Andon, O., Barrot, G., Mangin, A., Guirlet, M., Fehr, T., Snoeij, P., Saavedra, L., Koopman, R., and Fraisse, R.: Global analysis of scintillation variance: Indication of gravity wave breaking in the polar winter upper stratosphere, Geophys. Res. Lett., 34, L03812, doi:10.1029/2006GL028132, 2007.
Stockwell, R. G. and Lowe, R. P.: Airglow imaging of gravity waves -1 . Results from a small network of $\mathrm{OH}$ nightglow scanning imagers, J. Geophys. Res., 106, 17 185-17 203, doi: 10.1029/2001JD900035, 2001.

Suzuki, S., Shiokawa, K., Otsuka, Y., Ogawa, T., and Wilkinson, P.: Statistical characteristics of gravity waves observed by an allsky imager at Darwin, Australia, J. Geophys. Res., 109, D20S07, doi:10.1029/2003JD004336, 2004.

Torrence, C. and Compo, G. P.: A practical guide to wavelet analysis, Bull. Amer. Meteorol. Soc., 79, 61-78, doi:10.1175/ 1520-0477(1998)079〈0061:APGTWA $\rangle$ 2.0.CO;2, 1998.

Tsuda, T., Nishida, M., Rocken, C., and Ware, R. H.: A global morphology of gravity wave activity in the stratosphere revealed by the GPS occultation data (GPS/MET), J. Geophys. Res., 105, 7257-7273, doi:10.1029/1999JD901005, 2000.

Vincent, R. A. and Alexander, M. J.: Gravity waves in the tropical lower stratosphere: An observational study of seasonal and annual variability, J. Geophys. Res., 105, 17971-17 982, doi: 10.1029/2000JD900196, 2000.

Wang, L. and Geller, M. A.: Morphology of gravity-wave energy as observed from 4 years (1998-2001) of high vertical resolution U.S. radiosonde data, J. Geophys. Res., 108, 4489, doi:10.1029/ 2002JD002786, 2003.

Warner, C. D. and McIntyre, M. E.: An ultrasimple spectral parameterization for nonorographic gravity waves, J. Atmos. Sci., 58, 1837-1857, doi:10.1175/1520-0469(2001)058〈1837:AUSPFN $\rangle$ 2.0.CO;2, 2001.

Whiteway, J. A. and Carswell, A. I.: Lidar observations of gravity wave activity in the upper stratosphere over Toronto, J. Geophys. Res., 100, 14 113-14 124, doi:10.1029/95JD00511, 1995.

Williams, B. P., Fritts, D. C., Wang, L., She, C.-Y., Vance, J. D., Schmidlin, F. J., Goldberg, R. A., Müllemann, A., and Lübken, F.-J.: Gravity waves in the arctic mesosphere during the MaCWAVE/MIDAS summer rocket program, Geophys. Res. Lett., 31, L24S05, doi:10.1029/2004GL020049, 2004.

Wilson, R., Chanin, M. L., and Hauchecorne, A.: Gravity waves in the middle atmosphere observed by Rayleigh lidar - 1. Case studies, J. Geophys. Res., 96, 5153-5167, 1991a.

Wilson, R., Chanin, M. L., and Hauchecorne, A.: Gravity waves in the middle atmosphere observed by Rayleigh lidar - 2. Climatology, J. Geophys. Res., 96, 5169-5183, 1991b.

Wu, D. L. and Waters, J. W.: Gravity-wave-scale temperature fluctuations seen by UARS MLS, Geophys. Res. Lett., 23, 32893292, doi:10.1029/96GL02924, 1996a.

Wu, D. L. and Waters, J. W.: Satellite observations of atmospheric variances: A possible indication of gravity waves, Geophys. Res. Lett., 23, 3631-3634, doi:10.1029/96GL02907, 1996b. 